Zhao Yanchuang (Orcid ID: 0000-0002-0945-2818)

Title: Remotely sensed albedo allows the identification of two ecosystem states along aridity

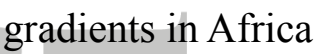

Yanchuang Zhao a,b,, Xinyuan Wang ${ }^{\mathrm{b}}$, Carlos J. Novillo ${ }^{\mathrm{c}}$, Patricia Arrogante-Funes ${ }^{\mathrm{c}}$, René

Vázquez-Jiménez $^{\mathrm{d}}$, Miguel Berdugo ${ }^{\mathrm{e}} \&$ Fernando T. Maestre ${ }^{\mathrm{e}, \mathrm{f}}$

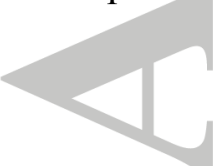

${ }^{a}$ College of Information Science and Engineering, Henan University of Technology, 450001,

\title{
Zhengzhou, China
}

${ }^{\mathrm{b}}$ Key Laboratory of Digital Earth Science, Institute of Remote Sensing and Digital Earth,

Chinese Academy of Sciences, 100094 Beijing, China

'Departamento de Tecnología Química y Energética, Tecnología Química y Ambiental y Tecnología Mecánica, Universidad Rey Juan Carlos, C/ Tulipán s/n, 28933 Móstoles, Spain

${ }^{\mathrm{d}}$ Cuerpo Académico UAGro CA-93 Riesgos Naturales y Geotecnología, Universidad Autónoma de Guerrero, Av/Lázaro Cárdenas s/n, CU, Chilpancingo, Guerrero 39070, México eDepartamento de Biología y Geología, Física y Química Inorgánica, Universidad Rey Juan Carlos, C/ Tulipán s/n, 28933 Móstoles, Spain

${ }^{f}$ Departamento de Ecología and Instituto Multidisciplinar para el Estudio del Medio "Ramon

This article has been accepted for publication and undergone full peer review but has not been through the copyediting, typesetting, pagination and proofreading process which may lead to differences between this version and the Version of Record. Please cite this article as doi: 10.1002/ldr.3338 
Margalef", Universidad de Alicante, Alicante, Spain

Corresponding author: Yanchuang Zhao; E-mail: zhych880615@126.com; Telephone number: 86-18623713725; Postal address: No.100 Lianhua Road, Zhengzhou Henan, China.

\section{E-mail addresses of other co-authors:}

Xinyuan Wang, wangxy@radi.ac.cn;

Carlos J. Novillo, carlos.novillo@urjc.es;

Patricia Arrogante-Funes, patricia.arrogante@urjc.es;

René Vázquez-Jiménez, rvazquez@uagro.mx;

Miguel Berdugo, mglberdugo@gmail.com;

Fernando T. Maestre, fernando.maestre@urjc.es

Running title: Two ecosystem states in African drylands

\section{Acknowledgements:}

This work was supported by the Strategic Priority Research Program of the Chinese Academy of Sciences [Grant No. XDA19030500], the National Key Research and Development Program of China [Grant No. 2016YFC0503302], the European Research Council [BIODESERT project, ERC Grant agreement $n^{\circ}$ 647038] and the Joint Ph.D. Training Program of the University of Chinese Academy of Sciences. 


\section{Abstract}

Empirical verification of multiple states in drylands is scarce, impeding the design of indicators to anticipate the onset of desertification. Remote sensing-derived indicators of ecosystem states are gaining new ground due to the possibilities they bring to be applied inexpensively over large areas. Remotely sensed albedo has been often used to monitor drylands due to its close relationship with ecosystem status and climate. Here we used a space-for-time-substitution approach to evaluate whether albedo (averaged from 2000 to 2016) can identify multiple ecosystem states in African drylands spanning from the Saharan desert to tropical Africa. By using latent class analysis we found that albedo showed two states (low and high; the cut-off level was 0.22 at the shortwave band). Potential analysis revealed that albedo exhibited an abrupt and discontinuous increase with increased aridity $(1-$ [precipitation/potential evapotranspiration]). The two albedo states co-occurred along aridity values ranging from 0.72 to 0.78 , during which vegetation cover exhibited a rapid, continuous decrease from $\sim 90 \%$ to $\sim 50 \%$. At aridity values of 0.75 , the low-albedo state started to exhibit less attraction than the high-albedo state. Low-albedo areas beyond this aridity value were considered as vulnerable regions where abrupt shifts in albedo may occur if aridity increases, as forecasted by current climate change models. Our findings indicate that remotely sensed albedo can identify two ecosystem states in African drylands. They support the suitability of albedo indices to inform us about discontinuous responses to aridity experienced by drylands, which can be linked to the onset of land degradation.

Keywords: albedo, multiple states, climate change, remote sensing, dryland degradation. 


\section{Introduction}

Drylands are defined as regions with an aridity index (AI, i.e., the ratio of mean annual precipitation to mean annual potential evapotranspiration) below 0.65 (UNEP, 1992). Desertification, defined as land degradation in arid $(0.05 \leq \mathrm{AI}<0.2)$, semi-arid $(0.2 \leq \mathrm{AI}<0.5)$ and dry sub-humid $(0.5 \leq \mathrm{AI}<0.65)$ areas resulting from various factors, including climatic variations and human activities (UNEP, 1992), is a serious environmental issue in drylands worldwide. It is estimated that $10-20 \%$ of dryland ecosystems are already degraded, and its consequences are currently affecting 250 million people living mostly in developing countries

(Reynolds et al., 2007). These numbers are likely to increase in the next decades because of projected increases in aridity (a fundamental driver of desertification (D'Odorico et al., 2013)) resulting from climate change (Huang et al., 2016), and forecasted population growth up to $\sim 4$ billion by 2050 (van der Esch et al., 2017). Furthermore, desertification also can influence areas located even thousands of kilometers away due to dust storms generated in desertified drylands (Millennium Ecosystem Assessment, 2005), and is a global environmental and socioeconomical issue of the greatest importance, as highlighted by the UN Convention to Combat

Desertification (Low, 2013).

The process of dryland desertification has often been studied using the theoretical framework of critical transitions (Scheffer et al., 2001). According to this theory, drylands exhibit two states (non-degraded vs. degraded) and the transition between them, triggered by disturbances such as increased aridity and grazing pressure, is abrupt and sudden, rather than gradual and continuous (Scheffer et al., 2001; D'Odorico et al., 2013). Multiple theoretical studies have further suggested the existence of multiple states and of abrupt, non-linear, shifts 
between them in drylands (Van de Koppel et al., 1997; Scheffer et al., 2001, 2009; Von Hardenberg et al., 2001; Rietkerk et al., 2004; Kéfi et al., 2007a; Corrado et al., 2014). Transitions between perennial and annual grasses and between forests, savannahs and treeless states have been found in savannahs (Lohmann et al., 2012) and tropical and subtropical areas (Staver et al., 2011; Hirota et al., 2011), respectively. Empirical studies in real dryland ecosystems are also identifying multiple states. Miller et al. (2011) found empirical evidence for three states (biocrust, grass-bare and annualized-bare) in a semiarid grassland ecosystem using an inventory data set from 72 plots on the Colorado Plateau, USA. Combining field data and high-resolution images obtained from Google Earth ${ }^{\circledR}$, Berdugo et al. (2017a) revealed the presence of two ecosystem multifunctionality (assessed by multiple soil variables related to carbon, nitrogen and phosphorus cycles) states in global drylands that co-occur near the boundary between arid and semi-arid zones (i.e. AI value $\sim 0.2$ ). As shifts between multiple states in drylands are often unannounced and difficult to reverse once they occur, it is imperative to understand the process triggering these shifts and to develop "early warning" indicators that could announce the transition before it occurs (Kéfi et al., 2014; Scheffer et al., 2009).

During the last decades, increasing research efforts have been devoted to the development and calibration of remote sensing-based indicators of desertification processes (e.g., Fensholt and Rasmussen, 2011; Liu et al., 2016; Karnieli et al., 2014; Robinove et al., 1980). Dryland degradation can increase the magnitude of albedo (defined as the ratio of the amount of electromagnetic radiation reflected by a body to the amount incident upon it) due to reductions in soil moisture and vegetation cover and to associated increases in soil erosion (Tripathy et al., 
1996; Robinove et al., 1980; Karnieli et al., 2014; Cierniewski et al., 2014). In addition, land surface albedo is a primary factor controlling the surface energy budget. The classic biogeophysical albedo-rainfall feedback proposed by Charney et al. (1975) has also been considered to be a plausible mechanism to explain the presence of multiple states in dryland ecosystems (see Scheffer et al., 2001). Thus, albedo may have the potential to reveal multiple states in drylands.

Despite the fact that albedo has been widely used to monitor ecosystem functioning and desertification (Tripathy et al., 1996; Robinove et al., 1980; Karnieli et al., 2014), to our knowledge no study has evaluated whether remotely sensed albedo can reveal the presence of multiple states in drylands. We aimed to do so along the aridity gradient defined by the transition between the Saharan desert and the wet climate of tropical Africa (Buontempo et al., 2010). Our study aims to: (i) assess whether remotely sensed albedo can reveal the presence of multiple states; (ii) compare the performance of albedo and vegetation cover to identify the presence of multiple states, as vegetation cover is a key factor determining ecosystem functioning in drylands worldwide (Gaitán et al., 2014; Soliveres et al., 2014) that is commonly used when assessing whether multiple states are present in terrestrial ecosystems (Hirota et al., 2011; Scheffer et al., 2012; Berdugo et al., 2017a); and (iii) identify vulnerable areas where critical transitions may occur if aridity increases, as forecasted by current climate change models (Huang et al., 2016).

\section{Materials and methods}

2.1. Study area 
We limited our study area to the climatic gradient existing between the Saharan desert and the wet climate of tropical Africa, which shows a wide natural aridity gradient (Fig. 1a). We retained for our analyses the arid, semi-arid and dry sub-humid areas within this region (Fig. 1b), as those have been acknowledge as critical areas where desertification can occur (UNEP 1992). Climate change and human activities are two major drivers of ecosystem change and land degradation in drylands (D'Odorico et al., 2013). To explore how ecosystems in our study area change in response to aridity, we masked out areas occupied by agricultural/urban uses and water bodies in any year during 2000-2015 by employing CCI land cover products (with a resolution of $300 \mathrm{~m})$ from the European Space Agency (ESA) (http://maps.elie.ucl.ac.be/CCI/viewer/, Fig. 1c). We also removed areas with high grazer density, i.e., $>15$ TLU (Tropical Livestock Units, an indicator used to standardize different livestock types and sizes (FAO, 2012), Fig. 1d), in accordance with the grazer (i.e., cattle, buffalo, sheep and goat) density values calculated by Petz et al. (2014). Furthermore, and to avoid variations in albedo resulting from topographical differences, we also removed the pixels with slope value $>5^{\circ}$ according to the SRTM (Shuttle Radar Topography Mission) $250 \mathrm{~m}$ Digital Elevation Data (http://gisweb.ciat.cgiar.org/TRMM/SRTM_Resampled_250m/, Fig. 1e). According to the climate dataset from WorldClim Version2 (Fick \& Hijmansn, 2017), mean annual precipitation and temperature (for 1970-2000) in our study area vary between 79 and $1693 \mathrm{~mm}$, and between 19.5 and $30.8^{\circ} \mathrm{C}$, respectively (Fig. S1a, b).

While the focus of our study was to explore whether drylands exhibited multiple states along an aridity gradient, we acknowledge that rainfed crops and livestock, two main land uses in our 
study area, can largely impact albedo signals. Therefore, we also re-analyzed our data by unmasking them (see Section 3.1 for further details).

\subsection{Remotely sensed albedo}

The actual albedo is determined by both atmospheric states and land surface reflective properties (Lucht et al., 2000; Wang et al., 2017). However, the white-sky (WSA) albedo is related purely to the properties of the land surface and is not affected by atmospheric conditions (Strahler et al., 1999). Zhao et al. (2018) have reported that WSA correlates with ecosystem multifunctionality, which has been found to exhibit two states and abrupt and discontinuous changes along aridity gradients in global drylands (Berdugo et al., 2017a). WSA (bihemispherical reflectance) is defined as albedo under the condition that the direct component is absent and the diffuse component is isotropic and thus is independent of solar zenith angle. Therefore, we employed the WSA derived from MODIS MCD43B3 BRDF/Albedo Model Parameters Product (Collection 5; NASA LP DAAC, 2002). The white-sky albedo products are produced by RossThick-LiSparse-Reciprocal (Ross-Li) BRDF models based on multiple cloud-cleared land surface reflectance data over 16 days from both Aqua and Terra Satellites (Lucht et al., 2000). Both narrow and broad albedo bands are provided every eight days since the year of 2000 with 1000 m resolution by MCD43B3 (Schaaf et al., 2002; Gao et al., 2005). Considering the marked difference in the reflectance of vegetation in the visible and nearinfrared spectral regions (Lucht et al., 2000), we used shortwave white-sky (SHO; 0.3-5.0 $\mu \mathrm{m}$ ), visible white-sky (VIS; 0.3-0.7 $\mu \mathrm{m}$ ) and near-infrared white-sky (NIR; 0.7-5.0 $\mu \mathrm{m}$ ) albedos. The quality of MCD43B3 WSA is indicated by the MCD43B2 BRDF_Albedo_Quality product with a flag of 0 (good quality data), 1 (useful data) and 255 (missing data). To avoid 
using data with poor quality, pixels with a flag of 255 were excluded. Missing data are usually due to the effect of clouds (Liu et al., 2009). This is not a severe issue in drylands, which are characterized by low precipitation and cloud cover. Finally, we obtained the average (Fig. S2bd) values for the three white-sky albedo types for 17 years (2000-2016) by using Google Earth Engine (Gorelick, 2012). We did this averaging process because of the uncertainty of the remotely sensed products used. Most of the pixels used in the study area had a low percentage of missing data during the 17-yr period studied (see Fig. S3). Because albedo is strongly seasonal in areas with a monsoonal climate such as that we studied, we also conducted separate analyses for dry (October to March) and wet (April-September) season (see Section 3.1 for further details).

2.3. Estimating vegetation cover and aridity values

The-cover of perenniat vegetation cover (in \%) was calculated from the yearly Terra MODIS Vegetation Continuous Fields (VCF) product, MOD44B (Collection 51; NASA LP DAAC, 2011). This product provides information on the cover of three components of vegetation at the end of the rainy season or during the growing season (Hansen et al., 2002; DeFries et al., 1998) with a global resolution: trees, non-tree vegetation and bare ground areas. The production algorithm is a linear model regression tree that employs Landsat Geocover data and surface reflectance of MODIS as inputs (Collection 51; NASA LP DAAC, 2011). Each pixel has a resolution of $250 \mathrm{~m}$ and three percent values which represent cover of the three components (NASA LP DAAC, 2011). The average vegetation cover (sum of the tree and non-tree vegetation cover) for 16 years (2000-2015) was calculated by using Google Earth Engine (Gorelick, 2012), and then resampled to a resolution of $1000 \mathrm{~m}$ to match that of the land surface 
albedo product used in this study. Vegetation in the study area is dominated by broadleaved trees, shrubs, grasses (Fig. S1d), and its cover, estimated from satellite, ranges from 0.4 to $99 \%$ (Fig. S1c).

The aridity index (AI) is often used to classify drylands, and to characterize their degree of dryness (UNEP, 1992; Middleton and Thomas, 1997, Millennium Ecosystem Assessment, 2005). We used aridity index values from Deblauwe et al. (2016). These were averaged for the period $2000-2014$, with a resolution of $0.05^{\circ}(\sim 5.5 \mathrm{~km}$ at the equator). To facilitate interpreting our results, we measured aridity level using 1 - AI (Delgado-Baquerizo et al., 2013); thus this metric increases with increasing aridity constraints. Aridity values within our study area vary between 0.35 and 0.95 .

\subsection{Analyzing multiple states using albedo data}

To avoid the uncertainty resulting from the dissimilar number of pixels present in the different aridity categories throughout the study area, we randomly selected 3000 pixels, with a minimum distance of $1 \mathrm{~km}$ far from each other, for arid, semi-arid and dry sub-humid areas. Then aridity (1 - AI) and the three white-sky albedo types were extracted for these 9000 pixels.

All these geoprocessing steps were executed using ArcGIS 10.2 (ESRI Inc., Redlands, CA, USA).

\subsubsection{Latent class analysis}

We used latent class analysis to test whether land surface albedo showed multiple modes in the study area. This approach can fit the data to single/multiple frequency distributions and has been commonly employed by studies evaluating multiple states in real ecosystems (Scheffer et al., 2012; Berdugo et al., 2017a; Hirota et al., 2011). To do so, we used the gmdistribution.fit 
function in Matlab R2009a (MathWorks Inc., Natick, Massachusetts, USA). This function uses an expectation-maximization algorithm to search the best fit for a certain number of normal distributions. We compared the Bayesian Information Criterion (BIC) obtained from the fits of the models with 1-5 classes. BIC is a goodness-of-fit criterion, whose minimum value corresponds to the most probable number of modes.

\subsubsection{Potential analysis}

The existence of multiple modes within a variable indicates the presence of contrasting ecosystem/states that point to a conspicuously different arrangement/functioning of the ecosystem. However, some studies revealed that such patterns found through spatial gradients may also be indicative of different dynamical states (Livina et al., 2010). In particular, when both modes of the variable under consideration vary abruptly through an environmental gradient and exhibit an area of co-existence along the gradient this is considered a pattern indicating possible abrupt transitions. A technique that allows to establish a link between multiple modes found through spatial gradients and stability is potential analysis. We used this analysis to explore whether the response of albedo to aridity matched this kind of pattern, which would be indicative of the existence of multiple states (Scheffer et al., 2001; Hirota et al., 2011; Berdugo et al., 2017a). This technique infers the position of stable equilibria directly from the data by estimating the basins of attraction for multiple states under the supposition that more stable conditions usually occur more frequently in a set of snapshots of the system (Livina \& Lenton, 2007; Hirota et al., 2011; Xu et al., 2016; Berdugo et al., 2017a). Thus, this technique attempts to link the fact that certain values distribute in multiple modes with dynamical stability associated to each of these values and is, therefore a way of analyzing abrupt changes using 
space for time substitution. As such, it is not free of caveats that should be taken into account when interpreting the results from a space-for-time-substitution analysis (Johnson \& Miyanishi, 2008). However, it allows to identify drastic changes in ecosystems with a plausible and important link to its dynamics (Eby et al., 2016). The basic assumption of this analysis is that, for the variable of interest, there is a generic underlying stochastic and dynamical system with a potential function

$$
d z=-U^{\prime}(z) d t+\sigma d w
$$

where $U(z)$ is the dynamical potential energy of the system as a function of its own state, $Z$ and $\sigma$ represent the state variable (here albedo) and the noise level respectively, $d w$ represents a noise term emerging from a Wiener process. According to a Fokker-Planck equation, which converts the probability density to the potential energy, the potential $U$ can be calculated as (Livina et al., 2010):

$$
U=-\frac{\sigma^{2}}{2} \log (P D F)
$$

where $P D F$ is the empirically derived probability density function of the variable of interest (here albedo). To facilitate the calculations, potential $U$ was scaled to $U / \sigma^{2}$. By doing so, the estimation of $\sigma$, which is difficult, can be avoided. The probability density of albedo was estimated using the ksdensity function in MATLAB, and a standard bandwidth is calculated as $1.06 \mathrm{~s} / \mathrm{n}^{0.2}$ ( $\mathrm{s}$ and $\mathrm{n}$ are the standard deviation and number of sample points, respectively; see Scheffer et al., 2012; Hirota et al., 2011 and Berdugo et al., 2017a).

We analyzed the abrupt nature of a shift in albedo states along the aridity gradient studied by tracking the local minima of the potential energy (local minima correspond to the different states; see Scheffer et al., 2012; Hirota et al., 2011 and Berdugo et al., 2017a) in a moving 
window. Moving windows subset the data under increasing aridity constraints and compute the potential energy and local minima for each iteration. By tracking the variation of these subsets along aridity gradients we can depict how potential energy and number of states change with increasing aridity. It has been reported that the correct rate of detecting states increased as the window size increased and a size of 400-500 data points showed $>90 \%$ correction rate of detection (Livina et al., 2013). However, the moving window size was set to 100 points in our study because (1) it reflects more details about the individual variation of the potential energy of albedo throughout the aridity gradient studied; (2) the results from size of 100 points were similar to that from 500 points (see Fig. S4); (3) this size had been used when processing geophysical data (Smith et al., 2008).

2.5. Mapping vulnerable areas to critical transitions in the face of climate change

Based on the potential analysis described above, we identified the aridity threshold at which sharp shifts in albedo may occur, i.e., from a low albedo state to high albedo state (see results below). Then we extracted the regions with low albedo values beyond this aridity threshold as vulnerable areas where critical transitions may occur in the study area if aridity increases, as forecasted by current climate change models (Huang et al., 2016). We further overlapped these areas with the global vegetation sensitivity index (VSI) of Seddon et al. (2016). This index quantifies the ratio of change of enhanced vegetation index (EVI, a vegetation index very similar to NDVI) respect to precipitation and temperature changes observed during the same period (2000-2015, see Seddon et al. 2016). It is an integrated metric assessing the sensitivity of ecosystems to climate perturbations, thus directly associated with dynamical properties of the system. With this overlapping procedure we wanted to check whether areas that are more 
likely to change their state due to increases in aridity (as indicated by decreases in the potential function calculated in the previous step) also show a higher sensitivity to external perturbations (a feature of systems that are close to cross a tipping point; Scheffer et al., 2001, 2009).

\section{Results}

3.1. Remotely sensed albedo revealed the presence of two states

The probability density of shortwave white-sky albedo (SHO; Fig. 2a), visible white-sky albedo (VIS; Fig. 2b) and near-infrared white-sky albedo (NIR; Fig. 2c) showed two significant modes, a low albedo of $0.14,0.05$ and 0.22 and a high albedo of $0.31,0.20$ and 0.43 for SHO, VIS and NIR, respectively. Cut-off levels for the two modes, defined by employing the locations of the local minima, were found at albedo values of $0.22,0.13$ and 0.31 for SHO, VIS, and NIR, respectively. For the three albedos evaluated, the BIC exhibited a sharp decline when the number of modes changed from 1 to 2 ; no apparent variations were observed from 2 to 5 modes (Fig. 2d). These results suggest that two modes of albedo are likely present in our study area.

Potential analysis provided additional details of how the two albedo modes changed along the aridity gradient evaluated (Fig. 3). There was a single state at low albedo values before the aridity value of 0.72 (Fig.3, inset c1), two states that started to co-occur persistently at aridity levels ranging from 0.72 to 0.78 (Fig. 3, insets c2-4) and again another single state, but of high albedo values, at higher aridity values (Fig. 3, inset c5). Interestingly, at the start of the aridity range where two albedo states co-occurred (i.e. aridity of 0.72 ), the low albedo state exhibited more attraction (lower potential energy) than the high albedo state (Fig. 3, inset c2), while the former started to exhibit less attraction (higher potential energy) than the latter at aridity values 
around 0.75 (Fig. 2, inset c3). An abrupt and discontinuous increase around aridity of 0.78 was observed regardless of the type of albedo considered (Fig. 3a, b and c).

These results did not change qualitatively when grazing areas were left unmasked (see Figs.

S5 and S6). When rainfed crop areas were left unmasked, the three albedo metrics still showed

two modes by latent class analysis (Fig. S7). However, the cut-off levels for the two modes $(0.24,0.14$ and 0.34 for SHO, VIS and NIR respectively) were not as sharp as those observed when these areas were masked (Fig. 2). In addition, the co-occurrence of the two albedo states was no longer observed in the aridity range between 0.72 and 0.78 , but albedo exhibited a quick change within this aridity range (Fig. S8).

Results from latent class analysis changed little when separating the wet and dry seasons (Fig. S9). For the potential analysis, the behavior of SHO in dry season (Fig. S10b) was very similar to that shown in Fig. 3. In the wet season, and albeit the behavior of SHO showed differences (Fig. S10a), significant changes in this variable still could be observed during the 0.72-0.78 aridity range. However, it must be noted that the duration of the wet/dry season changes along the aridity gradient evaluated, something that was not considered in our analyses.

3.2. States of vegetation cover along aridity gradients

Before the aridity level of 0.72 , when only the low albedo state was observed, vegetation cover was very high $(\sim 90 \%)$. During the aridity range when the two states albedo states co-occurred (0.72-0.78) vegetation cover exhibited a rapid, continuous decrease from $\sim 90 \%$ to $\sim 50 \%$. Beyond aridity values of 0.78 , when only the high albedo state was observed, vegetation cover showed a very high decrease rate (from $\sim 50 \%$ to $\sim 5 \%$ ). Vegetation turned very low at aridity values around 0.88 (Fig. 4). 
3.3. Identification of vulnerable areas where critical transitions may occur

We extracted areas with low albedo values $(<0.22$, the cut-off level for the two SHO albedo states identified) beyond the aridity value of 0.75 (see Section 4.2 for further explanations about why this value was selected) as vulnerable regions where critical transitions may occur if aridity increases as forecasted by climate change models (Fig. 5). These areas were mainly covered by shrubs, grasses and mosaics of both. Most of these areas had high/medium vegetation cover values (Shrub, 82\%; Grass 31\%, Mixed, 48\%), and showed low SHO values (around 0.17,

Table 1). In addition, most of them had moderate/high VSI values (Fig. 5). The average VSI value observed in vulnerable areas $(16.75 \pm 4.57$, mean \pm SD) was higher than that found in non-vulnerable areas $(13.98 \pm 3.99)$.

\section{Discussion}

4.1. Remotely sensed albedo revealed the presence of two ecosystem states

Regardless of the metric considered, we found empirical evidence of the presence of two albedo states in African drylands. The magnitudes of the states revealed by NIR were higher than that of states reveled by VIS and SHO. This agrees with the fact that both soil and vegetation usually have higher albedo in the near-infrared domain than in the visible domain (Satterwhite \& Henley, 1987; Lillesand et al., 2004). The two SHO states found were around 0.14 and 0.31, respectively. This is in accordance with the SHO values of that 0.14 and 0.35 employed by Charney (1975) to simulate regions covered with and devoid of plants, respectively, and to further uncover the albedo-rainfall feedback mechanism described by general climatic circulation models (Lofgren, 1995; Nicholson et al.,1998; Wang and Gao, 2004). Charney’s hypothesis postulates that such a magnitude of albedo change could cause a net decrease of 
radiative flux large-into the ground, leading to large decreases of rainfall in semi-arid areas in Africa, Asia and North America (Charney et al., 1977). This vegetation-climate feedback has been considered to be a plausible mechanism to explain the presence of two states in terrestrial areas (see Scheffer et al., 2001) and the shift from "wet" to "dry" states in areas like the Sahel within relatively short periods (see Foley et al., 2003), which are driven by contrasted wet and dry years, sometimes grouped in periods (Kusserow, 2017; Cherlet et al., 2018). However, we should note that Charney's hypothesis is not without dispute because it is heavily affected by spatial scale and convective parameterizations (Taylor et al., 2013), and because it contradicts with the "re-greening" of the Sahel, which is supported by both field and satellite observations (Olsson et al., 2005; Hutchinson et al., 2005; Rasmusse et al., 2015; Brandt et al., 2014).

We found empirical evidence that the use of remotely sensed albedo can identify two ecosystem states along spatial aridity gradients. The patterns described here suggest a substitution of these states along such gradients in a discontinuous and abrupt manner, thus matching the patterns expected from systems that exhibit the potential for critical dynamical transitions in response to increasing aridity (Livina \& Lenton, 2007). It is important to remind that our work does not provide dynamical evidences of such transitions in the study area as it is entirely based on a spatial gradient. Additional studies on the temporal dynamics of these ecosystems are needed to further corroborate that the studied ecosystems may suffer catastrophic shifts with climate change, preferably, with field validations or experimental approaches.

Regardless of their different magnitudes, the two albedo states revealed by the three albedo metrics considered co-occurred along aridity values ranging from 0.72 to 0.78 . Throughout this 
aridity range, vegetation cover exhibited a rapid and continuous, rather than abrupt, change. The differences observed in the behavior of albedo and vegetation cover were likely caused by a higher sensitivity of albedo (vs. percentage of cover) to changes in vegetation types. As shown in Fig. 6, the identified albedo states corresponded with multiple ecosystem types. In the aridity range between 0.72 and 0.78 , the low albedo state vegetation was dominated by shrublands, while grasslands dominated in the high albedo state (Fig.6a). These two vegetation types could be separated clearly by their albedo (Fig. 6a), while their cover values were close near this aridity range (Fig. 6b). It has been reported that albedo not only can be affected by plant cover but also by other structural properties of vegetation such as the height, crown size and shape of trees (McElhinny et al., 2005; Koukal et al., 2014). Therefore, albedo can capture more information about vegetation features than cover alone, and this may explain why the cooccurrence of two states can be revealed by albedo and not by vegetation cover alone.

It has been reported that tree cover derived from satellites can reveal multiple ecosystem states in pantropical (Hirota et al., 2011; Staver et al., 2011) and boreal (Scheffer et al., 2012) regions. However, Hanan et al. (2014) argued that the multiple states detected in these studies may result from the inherent features of the datasets used by these authors as the algorithm used to produce vegetation cover datasets is a statistical-reliant method. We would like to remark that this is not an issue in our study because the albedo data used are mainly produced by physical models rather than by statistical models.

It is worth to note that our results were slightly affected when rainfed crop areas were left unmasked, as the cut-off levels for the two modes (Fig. S7) were not as sharp as those observed when these areas were masked (Fig. 2). The abrupt, discontinuous change observed between 
the two albedo states were replaced by a quick, continuous change. This result suggests that extensive human activities performed in these areas may smooth observed albedo responses to changes in aridity. To further conclude about the mechanisms by which the abrupt nature of albedo shifts can be modulated, future studies need to be conducted in situ. Doing so is highly relevant as these studies may shed light on the mechanisms to lessen the consequences of abrupt ecosystem changes and help to define a safe-operating space against climate change within these areas (Rockström et al., 2009).

4.2. Areas vulnerable to regime shifts under increased aridity conditions

Our results showed that at aridity values around 0.75 , the low albedo state (with SHO values around 0.14 ) started to exhibit less attraction (higher potential energy) than the high albedo state (with SHO values around 0.31; Fig. 3c). We also found that around this aridity level (0.75) vegetation cover decreased rapidly (Fig. 4). Therefore, we speculate that when aridity crosses 0.75 , ecosystems at low albedo state, dominated by shrublands, tend to transit into the high albedo state, dominated by grasslands, a change that is accompanied by a rapid decrease of vegetation cover. Albeit shrubs with low albedo values could exist beyond aridity values of 0.75 (Fig. 6a), their cover decreased very rapidly as aridity increased (Fig. 6c). Herbaceous vegetation (with high albedo values) became prevalent under high aridity conditions (Fig. 6a). Our measurements cannot provide evidence for the mechanisms underlying the patterns observed, which need to be explicitly addressed by future studies performed at more local scales. However, it has been reported that a) forest and savannahs represent two alternative stable states driven by the complex interactions between precipitation and fire (N'Dri et al., 2012; Sankaran et al., 2005; Staver et al., 2011), and b) abrupt vegetation shifts from forests to 
savannahs and grasslands have occurred in some areas such as equatorial West Africa, the Amazon basin and some tropical areas in Colombia due to enhanced aridity (Willis et al., 2013; van der Hammen and Absy, 1994) or human activities (Cavelier et al., 1998; Nepstad et al., 1997). In addition, and within similar aridity gradients such as those we investigated, other studies carried out in drylands have found non-linear changes in significant ecological properties and mechanisms. These include drastic declines in ecosystem functioning accompanied by abrupt changes of vegetation spatial patterns from power law-like to nonpower law-like (Berdugo et al., 2017a, 2018), shifts in the mechanisms driving the structure of plant communities, from facilitation-driven to competition-driven (Berdugo et al., 2017b), the decoupling of soil carbon, nitrogen and phosphorus cycles (Delgado-Baquerizo et al., 2013) and changes in nitrogen turnover rates (Wang et al., 2014). Therefore, we hypothesize that at aridity levels around 0.7-0.8, many structural changes occurring on the ecosystem may influence each other through these interacting feedbacks. These results also support the idea that abrupt shifts in ecosystems such as those we studied can occur when aridity crosses 0.75 , and thus justify why used this aridity threshold to extract vulnerable areas to climate change (see Section 3.3).

Most of the vulnerable areas we identified had high/medium values of vegetation cover and low SHO values (Table 1). Aridity in these areas had been forecasted to increase by the end of this century due to ongoing climate change (Huang et al., 2016). Therefore, and with all the reservations imposed by the space for time substitution approach used (Johnson \& Miyanishi, 2008), we speculate that these areas may face a rapid decrease of vegetation cover, and may transition into a high albedo state, under forecasted aridity increases with climate 
change (Huang et al., 2016). Our results showed that most of them had also moderate/high VSI values (in Fig. 5) and that the average VSI value in vulnerable areas was higher than that in non-vulnerable areas. These results suggest a low resistance to climate perturbations and a higher possibility of critical transitions to occur in vulnerable areas (Seddon et al., 2016). As such, based on our results, these areas should be given priority when establishing mitigation actions against desertification and climate change within the study area.

We would like to remark that neither the vulnerable areas selected in our study nor the vulnerable areas or the VSI map from Seddon et al. (2016) are validated with field observations, and further monitoring is required to evaluate their potential vulnerability. This is necessary to assess other important factors affecting ecosystem states and vulnerability to climate change, such as recharge of groundwater and surface water (Richard \& Poccard, 1998), which are not considered in our study nor that of Seddon et al. (2016) and that need to be measured in situ.

\section{Conclusions}

By integrating remote sensing information with latent class and potential analysis, we identified two land surface albedo states (low and high) within African drylands. These albedo states cooccurred persistently along a critical range of aridity values between 0.72 and 0.78 , regardless of the albedo metric considered (shortwave, visible and near-infrared white-sky albedo). Albedo showed an abrupt and discontinuous increase with increases in aridity beyond a treshold found at aridity values around 0.75 . By identifying regions with low albedo values in areas beyond this threshold, we also provided the location of vulnerable areas where critical transitions may occur as a consequence of ongoing increases in aridity due to climate change. Overall, our findings highlight the potential of remotely sensed albedo metrics to indicate the 
vulnerability of dryland ecosystems to experience discontinuous transitions that could lead to their degradation. They also provide empirical verification of the existence of two states in African drylands, and support the use of remotely sensed albedo indices to identify multiple states and critical transitions in terrestrial ecosystems.

\section{Data Accessibility}

The aridity index we used is from Deblauwe et al. (2016), which is available from https://vdeblauwe.wordpress.com/download/. The land cover maps from European Space Agency (ESA) are archived at http://maps.elie.ucl.ac.be/CCI/viewer/. The three white-sky (shortwave, visible and near-infrared white-sky) metrics, vegetation cover percent and other information for the 9000 random points used are available from Figshare (https://figshare.com/s/c715f218d2612a8d813c).

\section{References}

Berdugo, M., Kéfi, S., Soliveres, S., \& Maestre, F.T. (2017a). Plant spatial patterns identify alternative ecosystem multifunctionality states in global drylands. Nature Ecology \& Evolution, 1, 0003. doi:10.1038/s41559-016-0003

Berdugo, M., Maestre, F.T., Kéfi, S., Gross N., Le Bagousse-Pinguet Y. \& Soliveres, S. (2017b). Species-specific adaptations determine how aridity and biotic interactions drive the assembly of dryland plant communities. Journal of Ecology, doi:10.1101/147181.

Berdugo, M., Soliveres, S., Kéfi, S., \& Maestre, F. T. (2018). The interplay between facilitation and habitat type drives spatial vegetation patterns in global drylands. Ecography, doi:10.1111/ecog.03795

Blois, J. L., Williams, J. W., Fitzpatrick, M. C., Jackson, S. T., \& Ferrier, S. (2013). Space can This article is protected by copyright. All rights reserved. 
substitute for time in predicting climate-change effects on biodiversity. Proceedings of the National Academy of Sciences, 110(23), 9374-9379. doi:10.1073/pnas.1220228110

Buontempo, C., Booth, B., \& Moufouma-Okia, W. (2010). Sahelian climate: past, current, projections. Met Office Hadley Centre, Devon, UK (available at: https://www.oecd.org/swac/publications/47092928.pdf)

Brandt, M. , Mbow, C. , Diouf, A. A. , Verger, A. , Samimi, C. , \& Fensholt, R. (2015). Groundand satellite-based evidence of the biophysical mechanisms behind the greening sahel. Global Change Biology, 21(4), 1610-1620. doi:10.1111/gcb.12807

Cavelier, J., Aide, T., Santos, C., Eusse, A., \& Dupuy, J. (1998). The savannization of moist forests in the sierra Nevada de santa marta, Colombia. Journal of Biogeography, 25, 901912. doi:10.1046/j.1365-2699.1998.00222.x

Charney, J., Stone, P.H., \& Quirk, W.J. (1975). Drought in the Sahara: a biogeophysical feedback mechanism. Science, 187, 434-435. doi:10.1126/science.187.4175.434

Charney, J., Quirk, W., Chow, S., Kornfield, J. (1977). A comparative study of the effects of albedo change on drought in semi-arid regions. Journal of Atmospheric Science, 34, 13661385. doi:10.1175/1520-0469

Cherlet, M., Hutchinson, C., Reynolds, J., Hill, J., Sommer, S., von Maltitz, G. (Eds.), (2018). World Atlas of Desertification, Publication Office of the European Union, Luxembourg.

Cierniewski, J., Karnieli, A., Kaźmierowski, C., Królewicz, S., Piekarczyk, J., \& Lewińska, K., et al. (2015). Effects of soil surface irregularities on the diurnal variation of soil broadband blue-sky albedo. IEEE Journal of Selected Topics in Applied Earth Observations \& Remote Sensing, 8, 493-502. doi:10.1109/JSTARS.2014.2330691

Corrado, R., Cherubini, A.M., \& Pennetta, C. (2014). Early warning signals of desertification transitions in semiarid ecosystems. Physical Review E, 90, 062705. doi:10.1103/PhysRevE.90.062705

D’Odorico, P., Bhattachan, A., Davis, K.F., Ravi, S., \& Runyan, C.W. (2013). Global desertification: drivers and feedbacks. Advances in Water Resources, 51, 326-344. doi: 10.1016/j.advwatres.2012.01.013

Deblauwe V., Droissart V., Bose R., Sonké B., Blach-Overgaard A., Svenning J-C, Wieringa J. J., Ramesh B. R., Stévart T. \& Couvreur T. L. P. (2016). Remotely sensed temperature and This article is protected by copyright. All rights reserved. 
precipitation data improve species distribution modeling in the tropics. Global Ecology and Biogeography, 25, 443-454. doi:10.1111/geb.12426

De Fries, R. S., Hansen, M., Townshend, J. R. G., \& Sohlberg, R. (1998). Global land cover classifications at $8 \mathrm{~km}$ spatial resolution: the use of training data derived from Landsat imagery in decision tree classifiers. International Journal of Remote Sensing, 19(16), 3141-3168. doi:10.1080/014311698214235

Delgado-Baquerizo, M., Maestre, F.T., Gallardo, A., Bowker, M.A., Wallenstein, M.D., Quero, J.L., Ochoa, V., Gozalo, B., García-Gómez, M., \& Soliveres, S. (2013). Decoupling of soil nutrient cycles as a function of aridity in global drylands. Nature, 502, 672. doi: $10.1038 /$ nature 12670

Eby, S., Agrawal, A., Majumder, S., Dobson, A. P., \& Guttal, V. (2017). Alternative stable states and spatial indicators of critical slowing down along a spatial gradient in a savanna ecosystem. Global Ecology and Biogeography, 26(6), 638-649. doi: 10.1111/geb.12570

FAO, 2012. In: Otte, J., Costales, A., Dijkman, J., Pica-Ciamarra, U., Robinson, T., Ahuja, V., Ly, C., Roland-Holst, D. (Eds.), Livestock Sector Development for Poverty Reduction: An Economic and Policy Perspective-Livestock's Many Virtues. FAO, Rome.

Fensholt, R., \& Rasmussen, K. (2011). Analysis of trends in the Sahelian 'rain-use efficiency'using GIMMS NDVI, RFE and GPCP rainfall data. Remote Sensing of Environment, 115, 438-451. doi:10.1016/j.rse.2010.09.014

Fick, S.E. and Hijmans, R.J. (2017). WorldClim 2: New 1-Km Spatial Resolution Climate Surfaces for Global Land Areas. International Journal of Climatology, 37, 4302-4315. doi:10.1002/joc.5086

Foley, J.A., Coe, M. T., Scheffer, M., \& Wang, G. (2003). Regime shifts in the sahara and sahel: interactions between ecological and climatic systems in northern africa. Ecosystems, 6, 524-532. doi:10.1007/s10021-002-0227-0

Gaitán, J. J., Oliva, G. E., Bran, D. E., Maestre, F. T., Aguiar, M. R., \& Jobbágy, E. G., et al. (2015). Vegetation structure is as important as climate for explaining ecosystem function across patagonian rangelands. Journal of Ecology, 102, 1419-1428. doi:org/10.1111/13652745.12273

Gao, F., Schaaf, C.B., Strahler, A.H., Roesch, A., Lucht, W., \& Dickinson, R. (2005). MODIS This article is protected by copyright. All rights reserved. 
bidirectional reflectance distribution function and albedo climate modeling grid products and the variability of albedo for major global vegetation types. Journal of Geophysical Research: Atmospheres, 110, D01104. doi:10.1029/2004JD005190

Gorelick, N. (2012). Google earth engine. In, AGU Fall Meeting Abstracts.

Hammen, T. V. D., \& Absy, M. L. (1994). Amazonia during the last glacial. Palaeogeography Palaeoclimatology Palaeoecology, 109, 247-261. doi: 10.1016/0031-0182(94)90178-3

Hanan, N.P., Tredennick, A.T., Prihodko, L., Bucini, G., \& Dohn, J. (2014). Analysis of stable states in global savannas: is the cart pulling the horse?. Global Ecology and Biogeography, 23(3), 259-263. doi:10.1111/geb.12122

Hansen, M. C. , Defries, R. S. , Townshend, J. R. G. , Sohlberg, R. A. , \& Carroll, M. (2002). Towards an operational modis continuous field of percent tree cover algorithm: examples using avhrr and modis data. Remote Sensing of Environment, 83:303-319. doi: 10.1016/S0034-4257(02)00079-2

He, T., Liang, S., \& Song, D.X. (2014). Analysis of global land surface albedo climatology and spatial - temporal variation during 1981-2010 from multiple satellite products. Journal of Geophysical Research: Atmospheres, 119. doi: 10.1002/2014JD021667

Hirota, M., Holmgren, M., Van Nes, E.H., \& Scheffer, M. (2011). Global resilience of tropical forest and savanna to critical transitions. Science, 334, 232-235. doi: $10.1126 /$ science. 1210657

Huang, J., Yu, H., Guan, X., Wang, G., \& Guo, R. (2016). Accelerated dryland expansion under climate change. Nature Climate Change, 6, 166-171. doi:10.1038/nclimate2837

Hutchinson, C.F., Herrmann, S.M., Maukonen,T., \& Weber, J. (2005). Introduction: the "greening" of the sahel. Journal of Arid Environments, 63(3), 535-537. doi: 10.1016/j.jaridenv.2005.03.002

Johnson, E. A., \& Miyanishi, K. (2008). Testing the assumptions of chronosequences in succession. Ecology letters, 11(5), 419-431. doi:10.1111/j.1461-0248.2008.01173.x

Karnieli, A., Qin, Z., Wu, B., Panov, N., \& Yan, F. (2014). Spatio-temporal dynamics of landuse and land-cover in the Mu Us sandy land, China, using the change vector analysis technique. Remote Sensing, 6, 9316-9339. doi:10.3390/rs6109316

Kusserow, H. . (2017). Desertification, resilience, and re-greening in the african sahel- a matter This article is protected by copyright. All rights reserved. 
of the observation period?. Earth System Dynamics, 8(4), 1141-1170. doi:10.5194/esd-81141-2017

Kéfi, S., Guttal, V., Brock, W.A., Carpenter, S.R., Ellison, A.M., Livina, V.N., Seekell, D.A., Scheffer, M., van Nes, E.H., \& Dakos, V. (2014). Early warning signals of ecological transitions: methods for spatial patterns. PloS one, 9, e92097. doi: 10.3390/rs6109316

Kéfi, S., Rietkerk, M., Alados, C.L., Pueyo, Y., Papanastasis, V.P., Elaich, A., \& De Ruiter, P.C. (2007a). Spatial vegetation patterns and imminent desertification in Mediterranean arid ecosystems. Nature, 449, 213. doi:10.1038/nature06111

Koukal, T., Atzberger, C., \& Schneider, W. (2014). Evaluation of semi-empirical brdf models inverted against multi-angle data from a digital airborne frame camera for enhancing forest type classification. Remote Sensing of Environment, 151, 27-43. doi: 10.1016/j.rse.2013.12.014

Le Houérou, H. N. (1989). The grazing land ecosystems of the African Sahel. Berlin; New York: Springer-Verlag.

Lillesand, T. M., Kiefer, R. W., Chipman, J. W. (2004). Remote sensing and image interpretation, Wiley India (P). Ltd., New Delhi.

Livina, V. N. , \& Lenton, T. M. (2007). A modified method for detecting incipient bifurcations in a dynamical system. Geophysical Research Letters, 34(3), $\quad$ L03712. doi:10.1029/2006GL028672

Liu, F., Chen, Y., Lu, H., \& Shao, H. (2016). Albedo indicating land degradation around the Badain Jaran Desert for better land resources utilization. Science of The Total Environment, 578, 67-73. doi:10.1016/j.scitotenv.2016.06.171

Liu, J., Schaaf, C., Strahler, A., Jiao, Z., Shuai, Y., Zhang, Q., Roman, M., Augustine, J.A., \& Dutton, E.G. (2009). Validation of Moderate Resolution Imaging Spectroradiometer (MODIS) albedo retrieval algorithm: Dependence of albedo on solar zenith angle. Journal of Geophysical Research: Atmospheres, 114, D01106. doi:10.1029/2008JD009969

Livina, V.N., Kwasniok, F., \& Lenton, T.M. (2010). Potential analysis reveals changing number of climate states during the last 60 kyr. Climate of the Past, 6, 77-82. doi:10.5194/cp-677-2010

Livina, V.N., Lohmann, G., Mudelsee, M., \& Lenton, T.M. (2013). Forecasting the underlying This article is protected by copyright. All rights reserved. 
potential governing the time series of a dynamical system. Physica A: Statistical Mechanics and its Applications, 392(18), 3891-3902. doi:10.1016/j.physa.2013.04.036

Lofgren, B.M. (1995). Sensitivity of land-ocean circulations, precipitation, and soil moisture to perturbed land surface albedo. Journal of climate, 8, 2521-2542. doi:10.1175/15200442(1995)008<2521:SOLCPA $>2.0 . C O ; 2$

Lohmann, D. , Tietjen, B. , Blaum, N. , Joubert, D. F. , \& Jeltsch, F. (2012). Shifting thresholds and changing degradation patterns: climate change effects on the simulated long-term response of a semi-arid savanna to grazing. Journal of Applied Ecology, 49(4), 814-823. doi: 10.1111/j.1365-2664.2012.02157.x

Low, P.S. (ed) (2013) Economic and Social impacts of desertification, land degradation and drought. White Paper I. UNCCD 2nd Scientific Conference, prepared with the contributions of an international group of scientists. Available from: http://2sc.unccd.int (accessed 26 March 2013.)

Lucht, W., Schaaf, C.B., \& Strahler, A.H. (2000). An algorithm for the retrieval of albedo from space using semiempirical BRDF models. IEEE Transactions on Geoscience and Remote Sensing, 38, 977-998. doi:10.1109/36.841980

Mcelhinny, C., Gibbons, P., Brack, C., \& Bauhus, J. (2005). Forest and woodland stand structural complexity: its definition and measurement. Forest Ecology \& Management, 218(1-3), 1-24. doi:10.1016/j.foreco.2005.08.034

Middleton, N., \&Thomas, D. (1997). World Atlas of Desertification. Arnold, London, UK.

Millennium Ecosystem Assessment. (2005). Ecosystems and human well-being: desertification synthesis. World Resources Institute, Washington, DC.

Miller, M.E., Belote, R.T., Bowker, M.A., \& Garman, S.L. (2011). Alternative states of a semiarid grassland ecosystem: implications for ecosystem services. Ecosphere, 2, 1-18. doi:10.1890/ES11-00027.1

Moulin, C., \& Chiapello, I. (2006). Impact of human-induced desertification on the intensification of sahel dust emission and export over the last decades. Geophysical Research Letters, 33, 510-527. doi:10.1029/2006GL025923

NASA LP DAAC. (2002). MODIS Terra + Aqua BRDF/Albedo Model Parameters 16-Day L3 Global 1000 m SIN Grid V005 (MCD43A1). USGS Earth Resources Observation and This article is protected by copyright. All rights reserved. 
Science (EROS) Center, Sioux Falls, South Dakota (accessed June 14, 2018, at https://lpdaac.usgs.gov/dataset_discovery/modis/modis_products_table/mcd43a1).

NASA LP DAAC. (2011). MOD44B MODIS/Terra Vegetation Continuous Fields Yearly L3 Global 250m SIN Grid V051. USGS Earth Resources Observation and Science (EROS) Center, Sioux Falls, South Dakota (accessed June 14, 2018, at https://lpdaac.usgs.gov/dataset_discovery/modis/modis_products_table/mod44).

N'Dri, A. B. (2012). Short term effects of fire intensity and fire regime on vegetation dynamic in a tropical humid savanna (lamto, central côte d'ivoire). Natural Science, 04(12), 10561064. doi:10.4236/ns.2012.412134

Nepstad, D. C., Klink, C. A., Uhl, C., Vieira, I. C., Lefebvre, P., \& Pedlowski, M., et al. (1997). Land-use in amazonia and the Cerrado of Brazil. Journal of the Brazilian Association for the Advancement of Science, 49, 73-86. (no doi)

Nicholson, S.E., Tucker, C.J., \& Ba, M. (1998). Desertification, drought, and surface vegetation: an example from the West African Sahel. Bulletin of the American Meteorological Society, 79, 815-829. doi:10.1175/1520-0477(1998)079<0815:DDASVA>2.0.CO;2

Olsson, L., Eklundh, L., Ardo, J. (2005). A recent greening of the Sahel-trends, patterns and potential causes. Journal of Arid Environment, 63:556-566. doi:10.1016/j.jaridenv.2005.03.008

Petz, K., Alkemade, R., Bakkenes, M., Schulp, C. J. E., Velde, M. V. D., \& Leemans, R. (2014). Mapping and modelling trade-offs and synergies between grazing intensity and ecosystem services in rangelands using global-scale datasets and models. Global Environmental Change, 29, 223-234. doi:10.1016/j.gloenvcha.2014.08.007

Prăvălie, R. (2016). Drylands extent and environmental issues. A global approach. EarthScience Reviews, 161, 259-278. doi:10.1016/j.earscirev.2016.08.003

Rasmussen, K. , Fensholt, R. , Fog, B. , Horion, S. , Rasmussen, L. V. , \& Reenberg, A. . (2015). Environmental change in the sahel: reconciling contrasting evidence and interpretations. Regional Environmental Change, 16(3), 1-8. doi: 10.1007/s10113-015-0778-1

Reynolds, J.F., Smith, D.M.S., Lambin, E.F., Turner, B., Mortimore, M., Batterbury, S.P., Downing, T.E., Dowlatabadi, H., Fernández, R.J., \& Herrick, J.E. (2007). Global desertification: building a science for dryland development. Science, 316, 847-851. doi: 


\section{$10.1126 /$ science. 1131634}

Rietkerk, M., Dekker, S.C., de Ruiter, P.C., \& van de Koppel, J. (2004). Self-organized patchiness and catastrophic shifts in ecosystems. Science, 305, 1926-1929. doi: 10.1126/science. 1101867

Robinove, C.J., Chavez, P.S., Gehring, D., \& Holmgren, R. (1981). Arid land monitoring using Landsat albedo difference images. Remote Sensing of Environment, 11, 133-156. doi: $10.1016 / 0034-4257(81) 90014-6$

Rockström, J., Steffen, W., Noone, K., Persson, Å., Chapin III, F. S., Lambin, E. F., ... \& Nykvist, B. (2009). A safe operating space for humanity. Nature, 461(7263), 472. doi: $10.1038 / 461472 \mathrm{a}$

Richard, Y., \& Poccard, I. (1998). A statistical study of NDVI sensitivity to seasonal and interannual rainfall variations in Southern Africa. International Journal of Remote Sensing, 19(15), 2907-2920. doi:10.1080/014311698214343

Sankaran, M. , Hanan, N. P. , Scholes, R. J. , Ratnam, J. , Augustine, D. J. , \& Cade, B. S. , et al. (2005). Determinants of woody cover in african savannas. Nature, 438(7069), 846-849. doi: $10.1038 /$ nature 04070

Satterwhite, M. B., \& Henley, J. P. (1987). Spectral characteristics of selected soils and vegetation in northern nevada and their discrimination using band ratio techniques. Remote Sensing of Environment, 23, 155-175. doi:10.1016/00344257(87)90035-6

Schaaf, C.B., Gao, F., Strahler, A.H., Lucht, W., Li, X., Tsang, T., Strugnell, N.C., Zhang, X., Jin, Y., \& Muller, J.-P. (2002). First operational BRDF, albedo nadir reflectance products from MODIS. Remote Sensing of Environment, 83, 135-148. doi:10.1016/S00344257(02)00091-3

Scheffer, M., Bascompte, J., Brock, W.A., Brovkin, V., Carpenter, S.R., Dakos, V., Held, H., Van Nes, E.H., Rietkerk, M., \& Sugihara, G. (2009). Early-warning signals for critical transitions. Nature, 461, 53. doi:10.1038/nature08227

Scheffer, M., Carpenter, S., Foley, J.A., Folke, C., \& Walker, B. (2001). Catastrophic shifts in ecosystems. Nature, 413, 591. doi:10.1038/35098000

Scheffer, M., Hirota, M., Holmgren, M., Van Nes, E.H., \& Chapin, F.S. (2012). Thresholds for This article is protected by copyright. All rights reserved. 
boreal biome transitions. Proceedings of the National Academy of Sciences, 109, 2138421389. doi:10.1073/pnas. 1219844110

Seddon, A., Macias-Fauria, M., Long, P.R., Benz, D., \& Willis, K.J. (2016). Sensitivity of global terrestrial ecosystems to climate variability. Nature, 531, 229-232. doi: 10.5287/bodleian:VY2PeyGX4

Smith T, Reynolds R, Peterson T, \& Lawrimore J. (2008) Improvements to NOAA's historical merged land-ocean surface temperature analysis (1880-2006). Journal of Climte, 21, 2283. doi: 10.1175/2007JCLI2100.1

Soliveres, S., Maestre, F. T., Eldridge, D. J., Delgado - Baquerizo, M., Quero, J. L., \& Bowker, M. A., et al. (2014). Plant diversity and ecosystem multifunctionality peak at intermediate levels of woody cover in global drylands. Global Ecology \& Biogeography, 23, 1408. doi: $10.1111 /$ geb.12215

Staver, A.C., Archibald, S., \& Levin, S.A. (2011). The global extent and determinants of savanna and forest as alternative biome states. Science, 334(6053), 230-232. doi: 10.1126/science. 1210465

Strahler, A.H., Muller, J., Lucht, W., Schaaf, C., Tsang, T., Gao, F., Li, X., Lewis, P., \& Barnsley, M.J.(1999). MODIS BRDF/albedo product: algorithm theoretical basis document version 5.0. MODIS documentation, 23, 42-47. (available at https://modis.gsfc.nasa.gov/data/atbd/atbd_mod09.pdf)

Taylor, C.M., Birch, C.E. , Parker, D.J., Dixon, N., Guichard F., \& Nikulin, G., et al. (2013). Modeling soil moisture-precipitation feedback in the Sahel: Importance of spatial scale versus convective parameterization. Geophysical Research Letters, 40. doi: $10.1002 / 2013$ GL058511

Tripathy, G., Ghosh, T., \& Shah, S. (1996). Monitoring of desertification process in Karnataka state of India using multi-temporal remote sensing and ancillary information using GIS. International Journal of Remote Sensing, 17, 2243-2257. doi: $10.1080 / 01431169608948771$

United Nations Environment Programme (UNEP). (1992). World Atlas of Desertification. Edited by N. Middleton and D. S. G. Thomas. London, UK:Edward Arnold Press.

United Nations Educational, Scientific and Cultural Organization (UNESCO). (1979). Map of This article is protected by copyright. All rights reserved. 
the world distribution of arid regions: Map at scale 1:25,000,000 with explanatory note. MAB Technical Notes 7, UNESCO, Paris.

van der Esch, S., ten Brink, B., Stehfest, E., Bakkenes, M., Sewell, A., Bouwman, A., Meijer, J., Westhoek, H., \& van den Berg, M., (2017). Exploring future changes in land use and land condition and the impacts on food, water, climate change and biodiversity: Scenarios for the UNCCD Global Land Outlook. PBL Netherlands Environmental Assessment Agency, Hague.

Van de Koppel, J., Rietkerk, M., \& Weissing, F.J. (1997). Catastrophic vegetation shifts and soil degradation in terrestrial grazing systems. Trends in Ecology \& Evolution, 12, 352356. doi:10.1016/S0169-5347(97)01133-6

Von Hardenberg, J., Meron, E., Shachak, M., \& Zarmi, Y. (2001). Diversity of vegetation patterns and desertification. Physical Review Letters, 87, 198101. doi:10.1016/S01695347(97)01133-6

Wang, C., Wang, X., Liu, D., Wu, H., Lü, X., \& Fang, Y., et al. (2014). Aridity threshold in controlling ecosystem nitrogen cycling in arid and semi-arid grasslands. Nature Communications, 5, 4799. doi: 10.1038/ncomms5799 (2014)

Wang, J., \& Gao, F. (2014). Albedo retrieval by remote sensing data. Remote Sensing Technology \& Application, 19, 295-300. (in Chinese; no doi)

Wang, Z., Schaaf, C.B., Sun, Q., Kim, J., Erb, A.M., Gao, F., Román, M.O., Yang, Y., Petroy, S., \& Taylor, J.R. (2017). Monitoring land surface albedo and vegetation dynamics using high spatial and temporal resolution synthetic time series from Landsat and the MODIS BRDF/NBAR/albedo product. International Journal of Applied Earth Observation and Geoinformation, 59, 104-117. doi:10.1016/j.jag.2017.03.008

Willis, K. J., \& Tovar, C. (2013). Determining the response of african biota to climate change: using the past to model the future. Philosophical Transactions of the Royal Society of London, 368, 20120491. doi:10.1098/rstb.2012.0491

Xu, C., Hantson, S., Holmgren, M., Nes, E.H., Staal, A., \& Scheffer, M. (2016). Remotely sensed canopy height reveals three pantropical ecosystem states. Ecology, 97, 2518-2521. di: $10.1002 /$ ecy. 1470

Zhao, Y., Wang, X., Novillo, C. J., Arrogante-Funes, P., Vázquez-Jiménez, R., \& Maestre, F. T. This article is protected by copyright. All rights reserved. 
(2018). Albedo estimated from remote sensing correlates with ecosystem multifunctionality in global drylands. Journal of Arid Environments, 157, 116-123. doi: 10.1016/j.jaridenv.2018.05.010
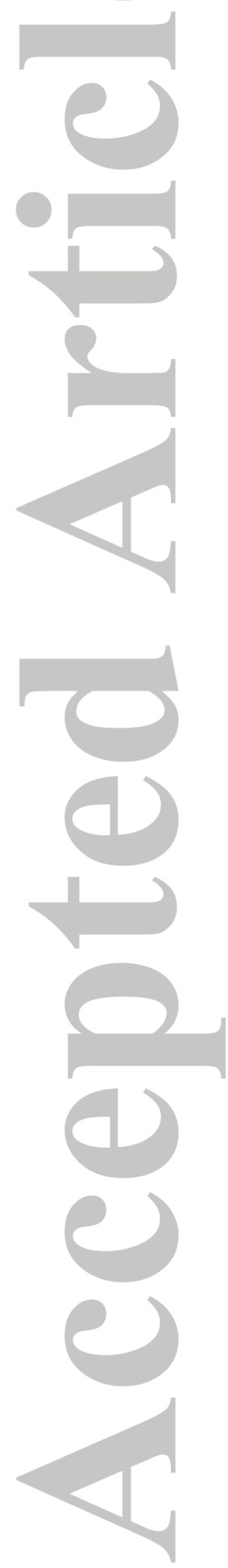

This article is protected by copyright. All rights reserved. 
Table 1 The characteristics of vegetation types in the vulnerable areas identified. SD is the standard deviation. SHO is the shortwave white-sky albedo.

\begin{tabular}{|c|c|c|c|c|c|c|c|c|c|}
\hline & \multicolumn{3}{|c|}{ Shrubland } & \multicolumn{3}{|c|}{ Grassland } & \multicolumn{3}{|c|}{ Mixed } \\
\hline & Aridity & SHO & Cover & Aridity & SHO & Cover & Aridity & $\mathrm{SHO}$ & Cover \\
\hline Mean & 0.78 & 0.17 & $82 \%$ & 0.89 & 0.17 & $31 \%$ & 0.86 & 0.16 & $48 \%$ \\
\hline $\mathrm{SD}$ & 0.03 & 0.02 & $13 \%$ & 0.05 & 0.03 & $22 \%$ & 0.05 & 0.02 & $22 \%$ \\
\hline Minimum & 0.75 & 0.08 & 0 & 0.75 & 0.1 & 0 & 0.75 & 0.11 & 0 \\
\hline Maximum & 0.95 & 0.22 & $95 \%$ & 0.95 & 0.22 & $93 \%$ & 0.95 & 0.22 & $94 \%$ \\
\hline
\end{tabular}

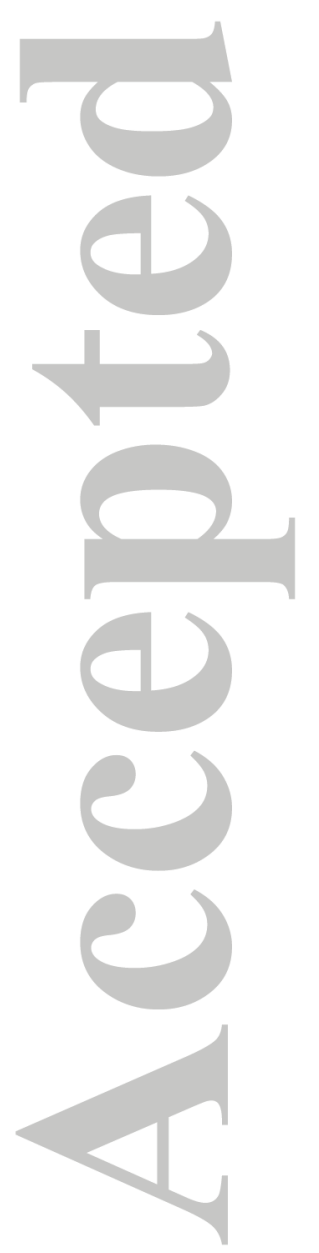



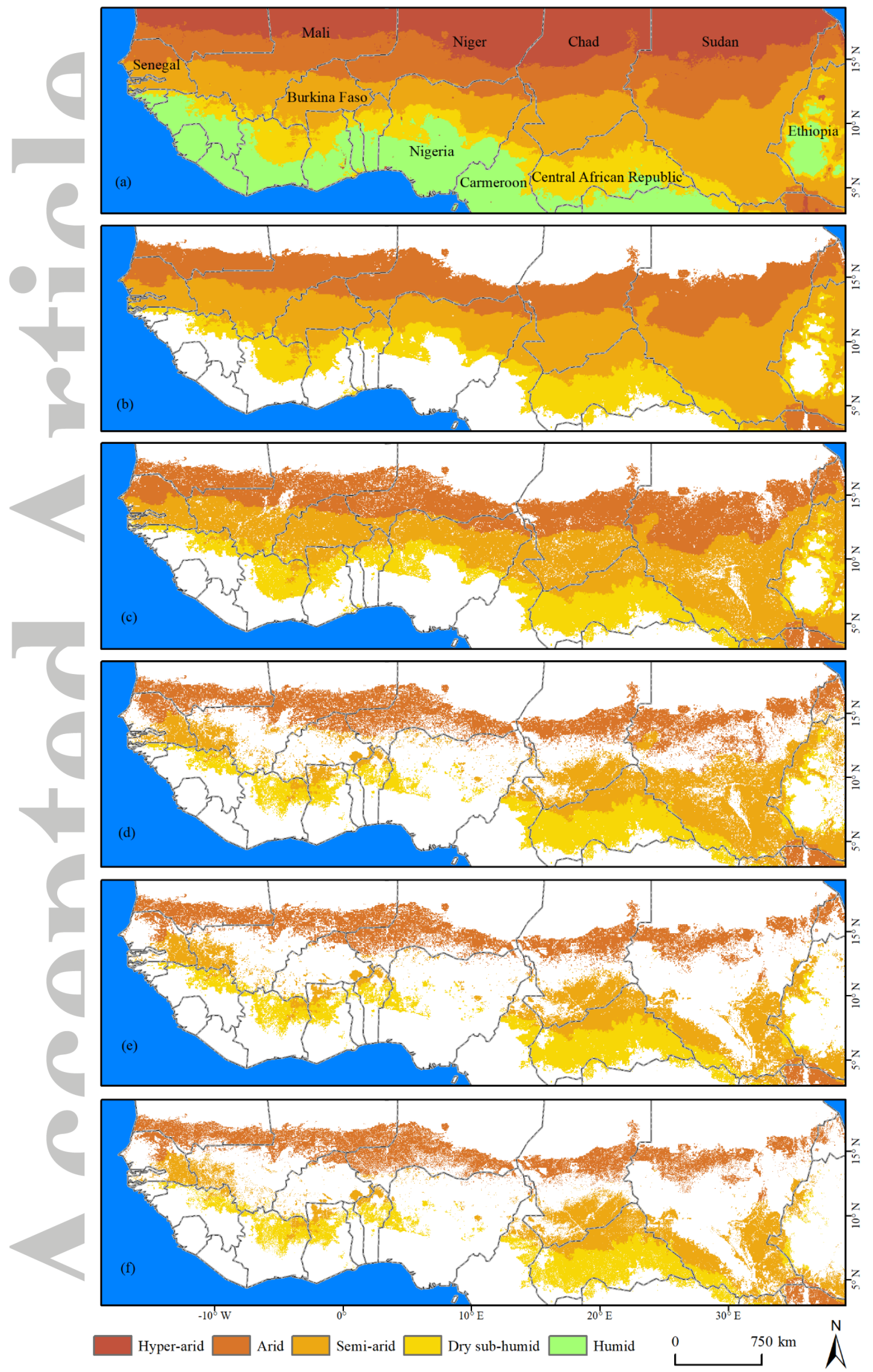

This article is protected by copyright. All rights reserved. 
Figure 1. Steps leading to the selection of the area analyzed in our manuscript. The study area is geographically defined by the transition between the Saharan desert and the wet climate of tropical Africa, characterized by a natural wide aridity gradient (Fig. 1a). We first masked humid/hyper-arid areas (b), followed by urban/irrigated/water (c) and rainfed crop areas (d). We then masked areas with a density of grazers $>15$ TLU (TLU is Tropical Livestock Units) and with a slope $>5^{\circ}$, resulting in the area selected for

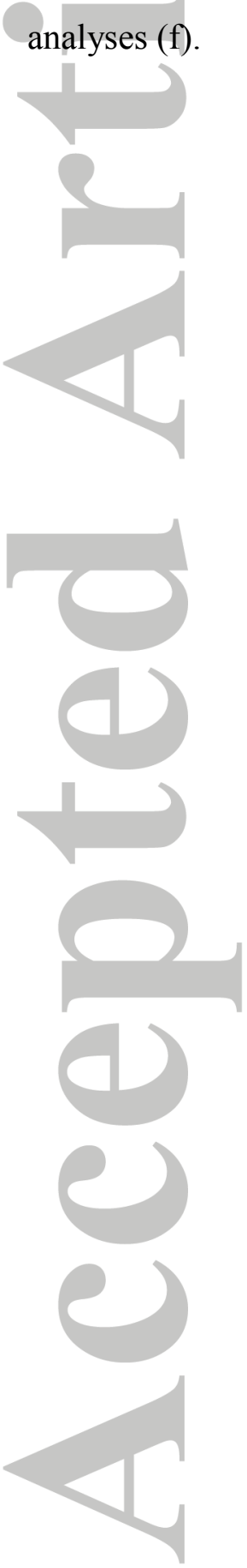



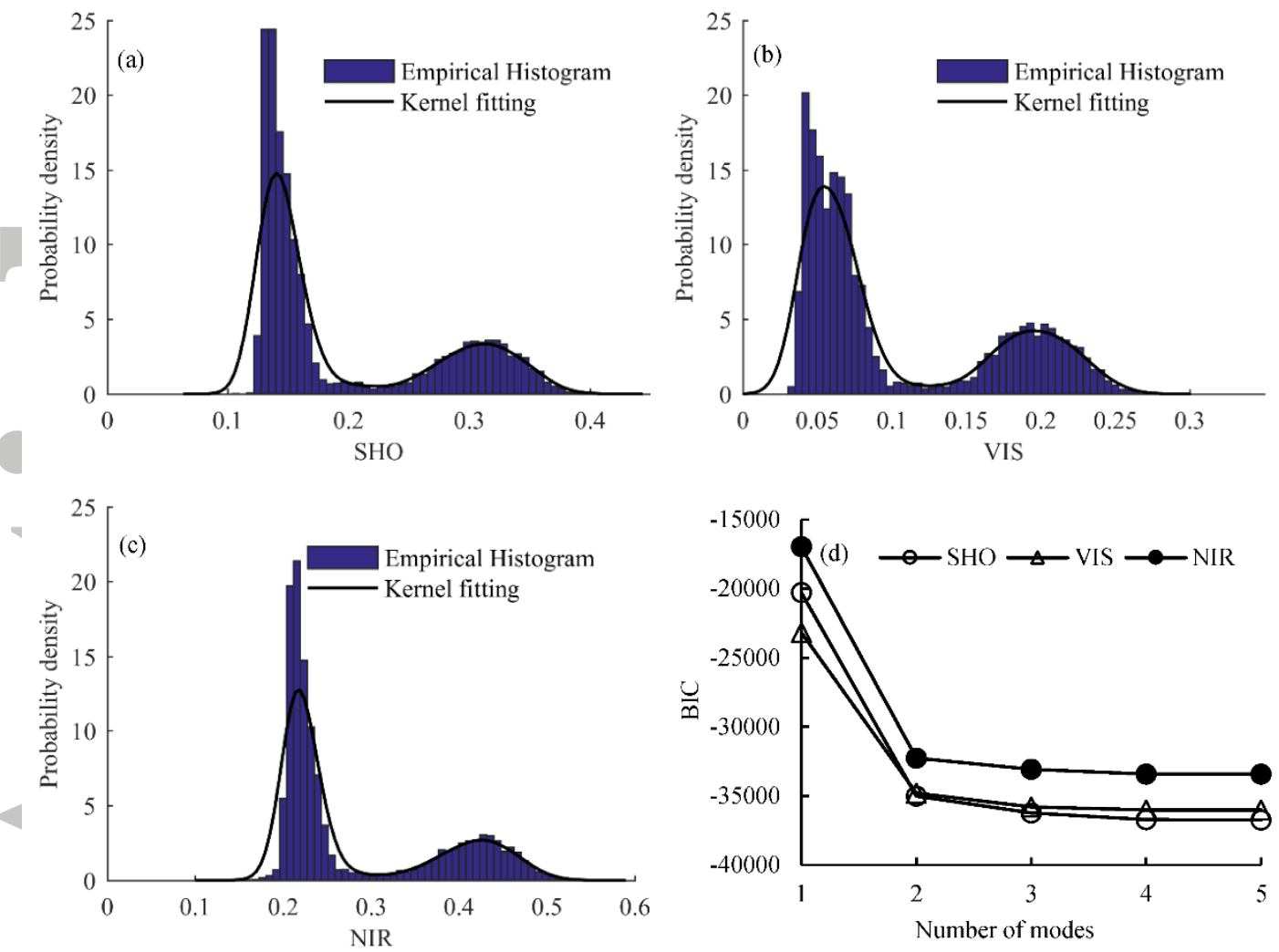

Figure 2. Probability density of shortwave white-sky albedo (SHO; a), visible white-sky albedo (VIS; b) and near-infrared white-sky albedo (NIR; c) across the study area. The curve shown in panels a, b and c was fitted by using a Gaussian kernel function. The comparison of fitting 1-5 normal distributions to albedos based on the Bayesian Information Criterion (BIC) is shown in panel $\mathrm{d}$. 

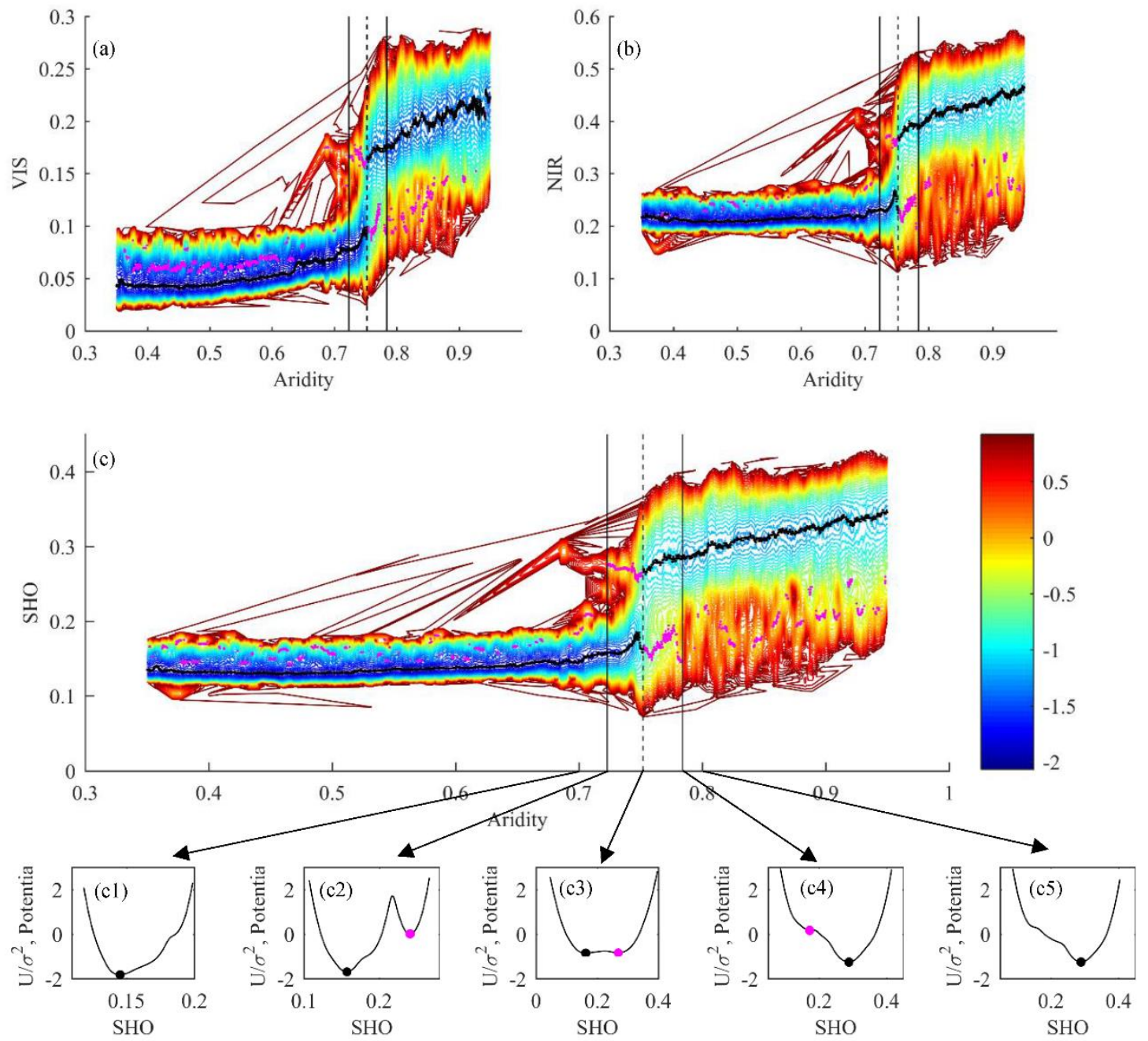

Figure 3. Variation of the states (i.e. local minima of the moving window with a size of 100 points) obtained from potential energy for the visible white-sky albedo (VIS; a), near-infrared white-sky albedo (NIR; b) and shortwave white-sky albedo (SHO; c) along the aridity gradient studied. The black and purple-red dots are both local minima obtained from the moving window; the potential energy at black dots is lower than at purple-red dots. The solid lines delimit the aridity range (i.e. $0.72-0.78$ ) is where the two states co-occur; the dashed line indicates the aridity level (i.e. 0.75 ) where the low albedo state starts to exhibit less attraction (i.e. higher potential energy) than the high albedo state. Contour lines (see color bar) represent the estimated potential energy. The (c1)-(c5) insets show details for the variation of the states of SHO along the aridity gradient studied. 


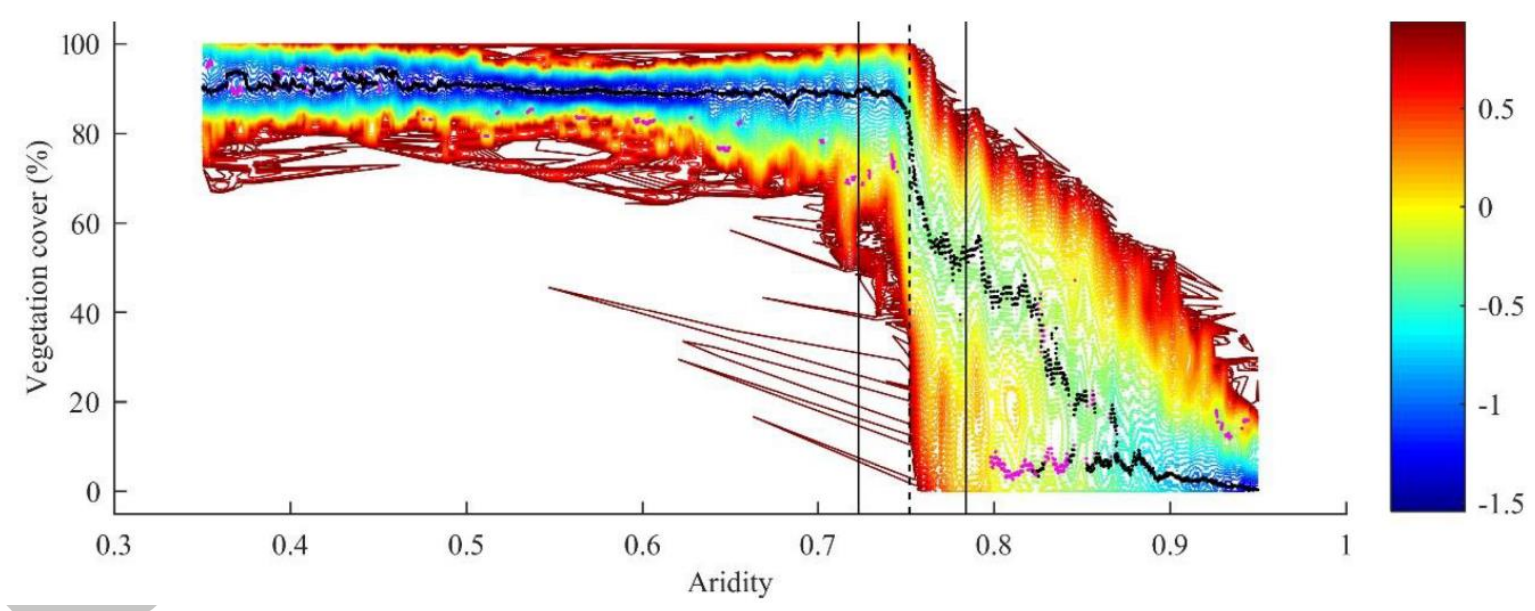

Figure 4. Variation of the states (i.e., local minima of the moving window with a size of 100 points) obtained from potential energy for vegetation cover along the aridity gradient studied. Rest of caption as in Fig. 3.

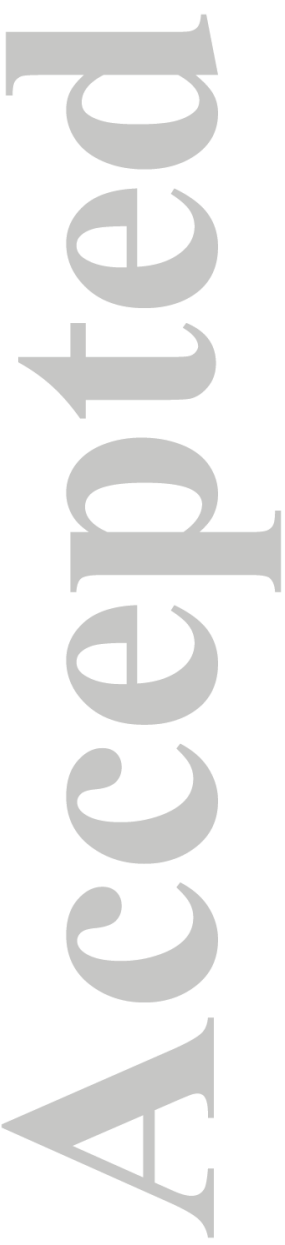




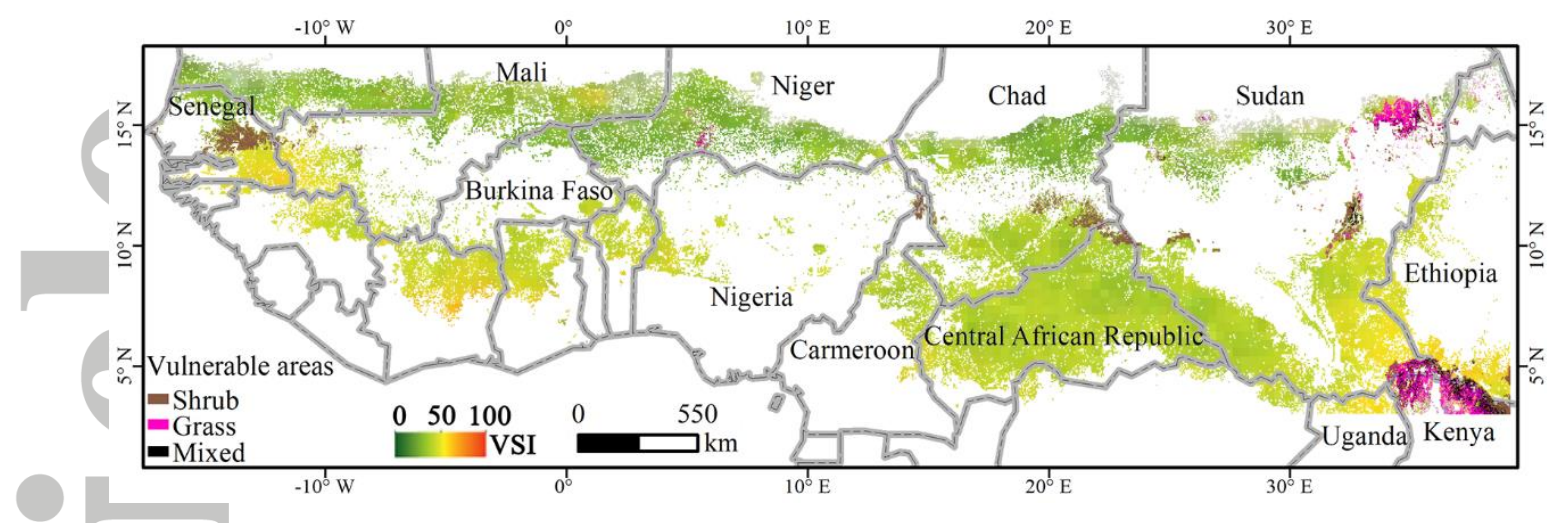

Figure 5. Vulnerable areas where critical transitions in albedo and vegetation may occur as aridity values increase due to climate change (marked in brown, pink and black for areas dominated by shrublands, grasslands and mixed vegetation). The colored and white areas in the background are the vegetation sensitivity index (VSI) from Seddon et al. (2016) and the regions excluded by our mask layers, respectively.

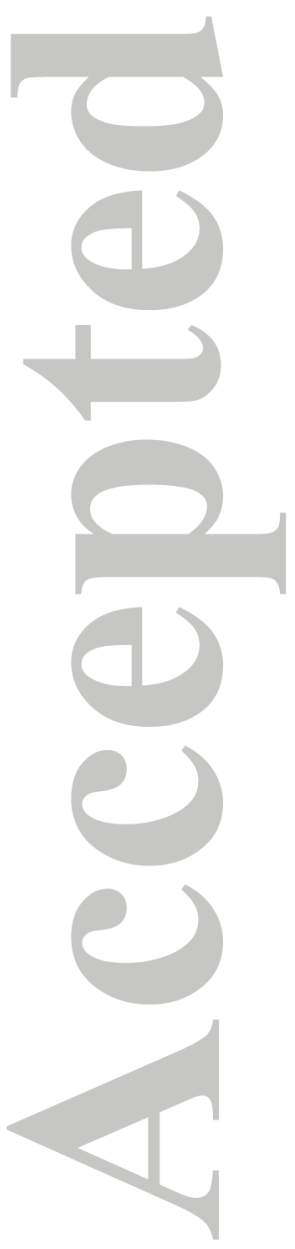



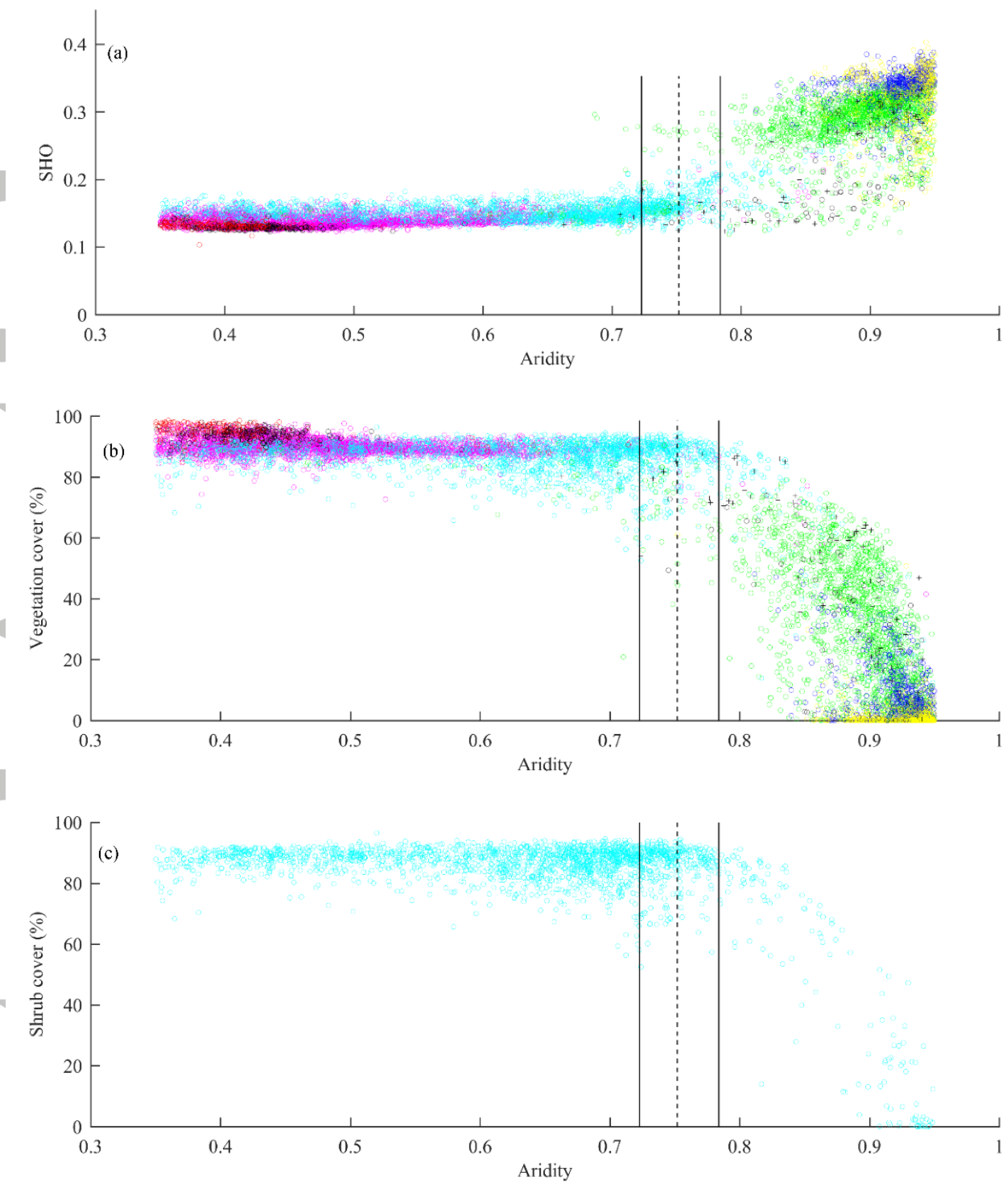

$\begin{array}{lccc}\text { O Broadleaved evergreen tree } & \text { Shrubland } & \text { O Sparse vegetation } & \text { O Mosaic herbaceous }(>50 \%) / \text { tree and shrub }(<50 \%) \\ \text { O Broadleaved deciduous tree } & \text { O Grassland } & \text { Bare areas } & + \text { Mosaic tree and shrub }(>50 \%) / h \text { herbaceous }(<50 \%)\end{array}$

Figure 6. Relationships between aridity and shortwave white-sky albedo (SHO; a), total (b) and shrub (c) cover. The dash and solid lines are same as those in Fig. 3. Different vegetation types are noted by different symbols/colours.

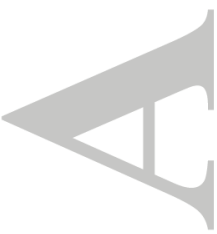

